\title{
THE INDIVIDUAL CHARACTERISTICS OF ADOLESCENTS BEING AT RISK OF INTERNET ADDICTION
}

\author{
Kiseleva T. G., Enzeldt N. V., Shmakov I. A. (Yaroslavl State Pedagogical \\ University after K.D. Ushinsky, Yaroslavl, Russia) \\ kisseleva2108@mail.ru, antosha_engels@mail.ru, ilia_8909@mail.ru

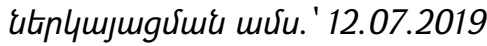

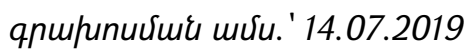

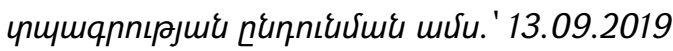

The Internet is an important part of the teenagers' life and source of the problem. One of them is an Internet addiction. In the article authors analyze the existing approaches to the study of the Internet addiction phenomenon, types, factors and stages of Internet addiction formation, as well as the motivation of Internet-addicted behavior. In the course of empirical research authors have defined some factors, formed the basis of the study of adolescent behavior. More than half of the survivors have a moderate or high susceptibility to Internet addiction, and the dominant symptoms in these adolescents are a violation of the communications, the avoidance of problems and responsibilities, self-dependence and anonymity as a special value. According to the study authors have made recommendations on the organization of socio-psychological and social-pedagogical work in prevention of Internet addiction in adolescents.

Keywords: Internet addiction, adolescents, impaired communication, avoidance of responsibility, independence and anonymity as a value.

The relevance of a subject of a research is determined by the following reasons: firstly, growth of the number of Internet users an average of 9\% a year that increases category potentially prone to an Internet addiction whose growth goes at the expense of minors [7]. Secondly, lack or not formation of skills of safe behavior in a network that leads to loss of information at users at the expense of infections by computer viruses, unauthorized access to personal information, etc. Thirdly, the growth of the number of persons with signs of Internet-addicted behavior [3.6].

The Internet environment is multipurpose and includes the diverse types of activity differing in character, purposes and motives. Every year the quantity of the resources used and created in the Internet increases, new social and age segments of the population are involved in networks. Especially brightly it is shown of the youth population, the majority of whom are super enthusiastic for the Internet. All this led to the fact that for society, there was relevant a problem of pathological use of the Internet, for the designation of this phenomenon I. Goldberg (1996) offered the term "Internet addiction" [quote. on 10]. 
Internet addiction is the phenomenon which is shown in a peculiar leaving real world while process of searching the network in the virtual world tightens the subject so that it is not able to function in an operational capacity in the real world [6]. The Internet addiction is included in group of not chemical addictions as a special manifestation of deviant behavior. National surveys studying of dependence on the Internet is presented in works of A.E. Voyskunsky, M.I. Drep, A.B. Kotlyarov, V.D. Mendelevich, V.Yu. Rybnikov and others [1.8]. Foreign researchers as M. Griffiths, J. Grokhol, J. Moreykhan-Martin, J. Suler, M. Finisher, K. Young brought up this problem for about 10-12 years before nationals [2,9,10].

The purpose of this work is the analysis of manifestations of Internet addicted behaviour in group of respondents from 14 to 27 years as the most subject to this type of an addiction. On the basis of the theoretical analysis of scientific literature on a problem of Internet addiction authors allocated the factors influencing formation the Internet addiction.

Our hypothesis was put forward - predisposition to Internet addiction will be higher if a teenager is characterized by the following qualities: lack of time control; avoiding of problems and responsibility; tendency to a lie; irritability; aspiration to anonymity and independence; violation of interpersonal communication; frustrated requirements; low self-assessment; physical indispositions.

The sample of the study was 383 persons from whom 194 persons - students at school at 9-11 classes aged from 14 up to 18 years, and 189 people - students of higher education institution aged from 18 up to 27 years participated. In selection of school students of the boys there were 98 people and 96 girls. The students participating in poll study in a pedagogical higher education institution, therefore the gender balance are shifted towards women's selection, namely: 38 men and 151 women. A choice of students of pedagogical higher education institution was made not casually since future teachers, having begun to work with children, will broadcast the same behavioral patterns which carriers are they.

Research methodology. Our study consisted of 4 stages. At the first stage we conducted a theoretical analysis of the causes and manifestations of Internet addiction, identified the factors of Internet addiction. At the second stage experts assessed the importance of each selected factor. By the method of expert assessment, we asked respondents to estimate the importance of these factors in the formation of an Internet addiction at leading experts in the field. 7 experts took part in the research: the staff of the regional narcological hospital, psychologists, social teachers, the staff of the police station for minors and protection of their rights. Group assessment can be considered as rather reliable only on condition of good coherence of answers of the interviewed experts, therefore statistical information processing included assessment of the degree of coherence of opinions of experts for which calculation weight coefficients of a concordance were used. We defined coherence of opinions by coefficient of a 
concordance of Kendall which showed a high coherence of opinions of experts that allowed to proceed with the research. These factors were also analyzed during our research. In the third stage, we compared the predisposition to Internet addiction in boys and girls, also in different age groups. At the fourth stage we identified a group of adolescents with a high level of Internet-addicted behavior and a group of adolescents with a low level, and then analyzed the psychological differences between these groups.

Analysis and interpretation of research results. We distributed respondents depending on the level of expressiveness of Internet dependence Distribution on levels showed the following picture presented in table 1.

\begin{tabular}{|c|c|c|c|}
\hline $\begin{array}{l}\text { Levels } \\
\text { Category of } \\
\text { respondents }\end{array}$ & $\begin{array}{l}\text { Low level (internet } \\
\text { addiction is not } \\
\text { expressed) }\end{array}$ & $\begin{array}{l}\text { Medium level } \\
\text { (Some signs of } \\
\text { internet addictions) }\end{array}$ & $\begin{array}{l}\text { High level (Formed } \\
\text { internet addiction) }\end{array}$ \\
\hline Overall sample. & $38,13 \%$ & $40,9 \%$ & $20,97 \%$ \\
\hline Men & $43,38 \%$ & $15,44 \%$ & $41,18 \%$ \\
\hline Women & $23,89 \%$ & $58,3 \%$ & $17,81 \%$ \\
\hline Pupils & $39,18 \%$ & $40,72 \%$ & $20,1 \%$ \\
\hline Students & $41,8 \%$ & $48,15 \%$ & $10,05 \%$ \\
\hline
\end{tabular}

Comparison of respondents on gender sign allowed to note obvious differences between men's and women's selection, namely: at men's group with the average level of Internet aadicted behavior is very little presented, but approximately identical percent of respondents belongs to group absolutely not subject to the influence of an addiction of this type or to group with signs of essential dependence on the Internet. Women's selection, on the contrary, is presented more by the average level of an Internet addiction; persons with high rates of dependence slightly more than $17 \%$ are revealed. This circumstance can be connected with higher levels of self-checking at women, or ability is more accurate and to fully structure free time.

Differences in age are not so striking: approximately identical percent of school students and students has the lowest level of Internet dependence. In the process of growing the number of persons with obviously expressed symptoms of an Internet addiction falls, perhaps this dynamic is affected not only by acquisition of life experience, but also feature of the social situation of development connected with training in higher education institutions.

Discussion. We considered groups of respondents with different levels of Internet addicted behavior for the purpose of identification of differences in factors signs of predisposition to an Internet addiction. The analysis of the answers of the respondents having obviously expressed Internet dependence level allowed making the rating of symptoms of this addiction. The leading signs are avoiding of problems and responsibility; independence and anonymity; violation of communications; a low self-assessment therefore further answers of respondents were analyzed according to the received rating. The aspiration to avoiding of problems can be considered as the desire of the person to 
leave from difficulties, to get rid of discomfortable psychological state, to take cover from growing, responsibility, boredom, depression. The general infantilization of society, aspiration not to solve, and to leave from problems, to pretend that they do not exist is observed, and the Internet gives a set of opportunities for entertainments which cause pleasant emotions and weaken sense of guilt, fear, shame and responsibility.

In men extreme trends are observed, namely respondents who or are ready to take the responsibility to the maximum dominate, or not to take it at all. Respondents with the average level of responsibility slightly more than $18 \%$ are revealed. For women, on the contrary, the average trend prevails. Women who are ready to charge themselves with all freight of responsibility, showing masculine type of behavior, in percentage about the same as the girls who are not wishing and seeking to answer pro se and to undertake the solution of possible problems.

Analyzing age dynamics, it is possible to notice that the level of responsibility increases in the process of growing of respondents. Perhaps, it is connected with finding of full legal responsibility or feature of training in higher education institution also promote more responsible behavior.

The second place in the rating of the factors contributing to an Internet addiction occupies aspiration to demonstration of independence and maintaining anonymity of communication in networks. The value of independence and anonymity, as a rule, is significant for the people wishing to abstract from the real world. The Internet represents such opportunity. In the network there is a possibility of creation of new images "I", original options for the self-presentations, the embodiment of the representations or imaginations impossible in everyday life. The Internet gives to such person's illusion of an opportunity to control the emotional state, to cause at will feeling of psychological comfort, to get rid of unpleasant emotions and thoughts. The anonymity and the actual impossibility of the check provided about itself with information, a possibility of connection in a virtual image real, desirable and entirely fictional characterologic and other features stimulates development of Internet dependence. As a disturbing trend we are forced to state prevalence of persons with the high level of anonymity, i.e. respondents are not ready to act under own name, giving about themselves reliable information. In a total amount of selection the percent of such people made more than $36 \%$. The same trend repeats also in the men's selection, namely: gradual increase in percent of the persons preferring anonymous communication on social networks, the message incomplete doubtful and sometimes and completely fictional information on.

Though statistically reliable differences between women's and men's selection it was not revealed, nevertheless anonymity trends in women's selection are presented in a different way. Women are inclined to post on the Internet more truthful information about themselves. Perhaps, this fact reflects more naive position in the social plan, doing female audience more vulnerable for Internet swindlers. 
Concerning the analyzed sign students were distributed in groups, approximately equally whereas at school, students the group preferring anonymous communication in social networks allowing to indulge in wishful thinking prevails almost twice.

In the third place among the factors indicating the formed Internet addiction, there is an underestimated self-assessment. This sign correlates with aspirations to anonymity in communication, social networks that was considered above. The Internet environment serves as a means of self-defense from a bad mood, feeling of pain and humiliation. Plunging into virtual reality, the person kind of protects himself from the problems, alarm, complexes. The virtual world can be used as a means of compensation of failures. It should be noted that" male respondents as much as possible, seek "to save face, the similar trend is traced at school students. Students on the degree of adequacy of a selfassessment are intermediate; most adequately women's selection estimates itself.

The last indicator which significantly exceeds the norm is violation in the field of communications. In general on all selection the thesis that the persons inclined to an Internet addiction have the lowest level of communicative skills was confirmed. It demonstrates that the presented groups of young people have problems in interpersonal communication, difficulties in social skill to communicate and adaptation in society. The analysis of separate categories of respondents gave more indistinct picture. So, in men's selection respondents on the level of skill to communicate were distributed approximately evenly, and in the women's selection the majority is made by respondents with the average level of sociability. The category "school students" completely corresponds to results in general of all selections, and at students the average level of communicative skills prevails.

The inability to control the time can be considered as a special case of low selforganization and self-discipline. On this indicator, women's selection was distributed approximately equally: slightly more than 30 percent of women $(32.79 \%)$ are able to distribute and plan the time, including time spent on social networks; as many women (32.39\%) experience some difficulties with planning and control of time, and $34.82 \%$ are not able to distribute time, chronically have its deficiency, including because of illegally long stay in the Internet. In men the level of self-checking has been higher, than in women, just $22.06 \%$ of men have experienced temporary difficulties because of abuse of the time spent on the Internet, and $43.38 \%$ of respondents answered that they are able to control themselves, are capable to stop, leave at any time social networks, to interrupt a game.

Comparing school students and students, it is possible to note the presence of a common problem at both age groups. As modern education does not without the use of Internet resources, the school students who are not able to operate time spent on social networks present a serious problem in terms of psychological wellbeing, their socialization and further success to live. Apparently from the results of a research, student's life introduces some amendments, but cardinally does not solve a problem. 
Anonymity of staying in social networks, formation of tendency to a lie becomes one of the negative consequences of using the Internet in everyday life, in particular and It will deceive that seriously complicates interpersonal communication, destroys family, undermines confidence of colleagues. The highest level of a lie was shown by women, perhaps, such behavior is a consequence of diffidence, fear to lose respect of people around, impossibility in real life to achieve progress or to make a desirable impression. The similar trend concerning a lie, only in more expressed look is observed at school students. Comparing results of these two groups, it is possible to assume the presence at the women's selection of signs of an infantilization and children's forms of self-defense. In student's selection the average level of a lie prevails, it was shown by $51.85 \%$ of respondents. Possibly, not only hobby for the Internet, but also student's life pushes to manifestations of a lie, but in a moderate form that speaks about the ability of students to predict consequences of the words and actions, including deception. Liars and honest in the men's selection were evenly distributed. We connect such result with the fact that men have more opportunities to show off show themselves that excludes need to lie about it. On the other hand, requirements and expectations of society to men are overestimated, it is extremely hard to correspond to them, therefore men who fall short of social standards of a masculinity and success resort to deception, it is easier to make all this through virtual communication. This fact sets thinking that, since a school bench, it is necessary to create conditions for self-realization and self-affirmation of the person, then it will be an effective way of preventing not only Internet dependence, but also a number of other social addictions.

Unfairly long stay in the Internet leads to emergence of a number of diseases, therefore not only psychologists, sociologists, teachers, but also physicians speak about this problem. Among the obtained data attracts attention the fact that among men's selection the highest percent (53.68\%) feeling physical weakness, an indisposition after a long stay in the Internet is noted. In it we find two explanations. First, in men's selection the high level of Internet and dependent behavior, therefore the indisposition is the natural consequences of such actions is noted. Secondly, in researches of psychiatrists it is often indicated that morbid depression meets more often in men's population, therefore it of the experience of the general weakness and an indisposition in connection with abuse of the Internet can be a special case of manifestation of male morbid depression. School students and students showed approximately identical answers concerning concern about the health.

Unsatisfied requirements induce the person to the actions directed to their satisfaction or replacement. Survey conducted for us showed that the highest level of unsatisfied requirements is observed at school students, it is explainable due to age still a lot of things are inaccessible to them, but it is very seductive. The problem consists that school students direct the efforts not too constructive ways of achievement of the desirable purposes, and go from problems in the virtual world, therefore, it is 
impossible to solve an Internet dependence problem at teenagers if parents ignore the interests and needs of own children. Qualitative differences in levels of frustration of requirements between men and women are not revealed, the differences have quantitative character. In both groups of respondents it is possible to state the average level of satisfaction/dissatisfaction of requirements, only at women this group makes the vast majority (81.38\%), and of men - is twice less (41.91\%) whereas the number of faces is essential frustrated among men almost five times exceeds similar group among women. This trend can hide or provoke a number of negative social consequences in the men's selection, such as alcoholism, suicide behavior, gambling addict and another.

A lot of things depend on emotional and strong-willed self-control of the person, including ability to resist to various temptations, such as Internet therefore the last factor which was analyzed in our research in connection with an Internet addiction concerned emotional security / imbalance. Comparison on gender sign yielded quite predicted results: men react to the taking place events much more quietly, or try not to show the emotional state. Such a model does not contradict the stereotypes of social behavior which developed in our society. Results of comparison on age sign pleasantly surprised us. It is revealed that school students have the average level of self-control and control over the emotional state, and students surpass school students with the ability to constrain emotions. $42.86 \%$ of the interviewed students have the lowest level of emotional imbalance and irritability.

Conclusions. The data obtained in a research confirm the need of carrying out with teenagers and youth of special psychological intervention work on the following directions:

1) formation of communicative and organizational skills, development of competence of communication, adequate perception of criticism, ability to listen and understand interlocutors;

2) development of skills of self-checking and self-control, conscious goal-setting, responsibility, ability to solve the problems independently;

3 ) increase in a self-assessment and consciousness of the identity of the teenager, formation of self-confidence, development of abilities of adequate self-estimation, ability to critical perception of reality.

The conducted research offers the prospects of further development and studying of a problem of identification of predisposing to Internet dependence at various categories of respondents.

\section{References}

1. Chatter M.I. Internet-zavisimost as an object of a scientific reflection in modern psychology //Knowledge. Understanding. Ability. -2009. №2. - 189-193p. 
2. Griffiths M. Internet addiction: Faet or fiction? // Psychologist. 1999. V. 12(5). 246-250p.

3. Hall A. Internet addiction: the student's case study by means of the best methods of informative therapy //The Magazine of consultation of mental health. - 2001. Volume 23. № 4 - 312-327p.

4. Kiseleva T. G. Specific features of the teenagers predisposed to Internet dependence//the Bulletin of the Kostroma state university. Series: Pedagogics. Psychology. Sotsiokinetika, 2017. T. 23. № 3.- 46-50p.

5. Manashkin M.M., Kiseleva T.G. Sotsialno-psychological portrait of the young man predisposed to an Internet addiction//The Innovative potential of youth: information, social and economic security. Materials of the International youth research conference. Ministry of Education and Science of the Russian Federation; Federal Agency for Youth Affairs (Rosmolodezh); "Presidential Center of V.N.Yeltsin" Fund; Department of youth policy of Sverdlovsk region; Moscow State University of M.V. Lomonosovai other / Under the general edition of A.V. Ponomarev, 2017. 750-754p.

6. Saglam F.A. Internet-addiktion of teenagers as form of manifestation of deviant behavior //Pedagogical education and science. - 2009. № 5. - 88-91p.

7. Varlamova S.N. Internet-zavisimost of youth of megalopolises: criteria and typology /Monitoring, 2015. № $2-165-182 \mathrm{p}$.

8. Voyskunsky A.E. Psychological researches of a phenomenon of an Internet addiction //The 2nd Russian conference on Ekopsicentre ROSS, 2000. 251-253 p.

9. Young K.S. The diagnosis is Internet dependence //The World the Internet. 2000. №2. - 24-29p.

10. Yuryeva L.N. Computer dependence: formation, diagnostics, correction and prevention //Dnipropetrovsk: Thresholds. 2006. - 80-82p. 